\title{
los recubrimientos de plásticos como defensa de los tubos de hormigón frente a la corrosión ejercida por suelos y aguas agresivas
}

\begin{abstract}
Comentarios realizados por el señor Garcia de Paredes, Jefe de la Sección de Estudios Especiales sobre Conglomerantes del I. T. C. C., acerca de una comunicación presentada en el III Congreso Internacional del Hormigón puesto en obra, por el Dr. Ing. Don Carlos Carril Carvajal, Director General de "Materiales y Tubos Bonna, s. A.".
\end{abstract}

En la conducción de líquidos, y aún de gases, el tubo de hormigón constituye un valioso medio auxiliar, ya que presenta sobre el tubo de metal ventajas, cifradas principalmente en su mayor durabilidad.

Esta cualidad de poco alterable, que en toda obra es de tanta importancia, adquiere en las redes destinadas a la conducción de flúidos destacado interés, debido a que, por lo general, las tuberías se sitúan, o enterradas o en lugares de acceso poco fácil, lo que supone un incremento en las dificultades para su adecuado cuidado.

Los técnicos del I. T. C. C. han tenido que resolver muchas consultas relativas a estos problemas, y recordamos con especial complacencia las interesantes sugerencias que un ilustre ingeniero nos hizo acerca del modo cómo resolvió la protección de tubos metálicos, mucho más vulnerables en su caso que los de hormigón. ¡Ojalá se resuelva a publicar sus ingeniosos procedimientos!

Ambientando así el tema, puede juzgarse mejor el gran interés de la ponencia que sobre "Protección de los tubos de hormigón contra el ataque por terrenos y aguas agresivas" han presentado al III Congreso Internacional de Manufacturas en Hormigón, celebrado en Estocolmo durante los días 16 al 22 del próximo pasado junio, el doctor don Carlos Carril Carvajal, Ingeniero de Caminos, y los señores M. J. G. Hendrickson, Jr., y don Juan F. García Balado. Esta ponencia se incluyó bajo el título general "Unión hormigón-plástico".

En el preámbulo advierten los ponentes que "el objeto de esta exposición es estudiar los terrenos y aguas agresivas para el hormigón, y la posibilidad de utilizar revestimientos de materias plásticas capaces de evitar el ataque". Ya es significativo, y personalmente nos alegra, encontrar la afirmación de "que, en general, bastará, para alcanzar la durabilidad con garantías suficientes, la elaboración y curado de los tubos realizada de acuerdo con los procedimientos modernos".

Se inicia la ponencia con una breve referencia a los componentes del cemento y su contribución a los fenómenos de fraguado $y$ endurecimiento del hormigón; es decir, sin olvidar la preponderante influencia ejercida por la elaboración y el curado, se centra en el conglomerante la sede de la futura permanencia de la obra. Este criterio sirvió de base al artículo que, con el título de "Agresivos de los conglomerantes", se publicó en "Informes de la Construcción" el año 1953. 
A continuación destacan los ponentes la influencia que la cal libre en el hormigón ejerce sobre la vulnerabilidad del mismo, y exponen las formas que el llamado "indice de resistencia a la agresividad" ha tomado según los diversos autores, especialmente Grün (Tonindustrie Zttg., 65-I-1944) y Meter-Grolman (Monografía núm. 182 del $I$. T, C. C.), lo que les lleva a fijar cuàl seria la composición más adecuada para que un portland resistiese con éxito el ataque químico.

Esta composición ideal es:

$$
\begin{aligned}
& \mathrm{C}_{2} \mathrm{~S}=50 \% ; \mathrm{CS}<45 \% ; \mathrm{C} . \mathrm{AF}=6 \% ; \mathrm{CaO} \text { libre } \leqslant 0,5 \% \\
& \mathrm{C}_{2} \mathrm{~A}=5 \text { a } 6 \% ; \text { Alcalis } \times 0,7=1 \% ; \mathrm{CaSO}_{4}=3,5 \%
\end{aligned}
$$

No descartan los autores la posibiiidad de uti izar otros conglomerantes en la fabricación de tubos de hormigón. En general, fijan la cantidad minima de conglomerante, como cifra aproximada según la naturaleza del mismo, en $400 \mathrm{~kg}$ por metro cúbico.

Seguidamente, describen los agentes agresivos para el hormigón y su posible mecanismo de actuaclón, coincidiendo esta descripción con el contenido del artículo ya mencionado, la recomendación incluida en la norma H58 del I. T. C. C., la norma UNE 41-124 del Instituto Nacional de Racionaltzación y el "Apercú bibliografique", de Nicol. Creemos que existe un error de imprenta cuando se cita el ataque ejercido por los aceites y grasas vegetales $y$ minerales, al declr que los primeros no atacan en tanto se encuentren libres de ácldo; siempre supusimos que esto se acomodaba mejor a los productos minerales, ya que los otros se hidrolizan debido a la alcalinidad amblental propia del hormigón.

Consideran potencialmente como aguas agresioas aquellas de $\mathrm{pH}<5$ ó $>12$ y las que contienen MgSO $\supseteq 0,1 \mathrm{~g} / l$ y CaSO $\supseteq 0,2 \mathrm{~g} / l$, además de las muy puras con menos de seis grados hidrotimétricos (¿franceses?).

LOS MEDIOS PROTECTORES descritos se pueden agrupar en:

1.- Tratamientos correctores, fisicos o quimicos, de las aguas, apilcados antes de su entrada en la red de tubos.

2." Utilización de conglomerantes distintos del portland, que en nuestro Pliego se marcan con la letra $P$.

3.- Adiciones modificadoras de alguna cualidad del hormigón, principalmente las que incrementan la compacidad del mismo. Son tan reclentes algunas que se carece de suffiente experiencia.

\section{4." Tratamientos superficiales:}

a) Fluatos o fluosilicatos de zinc y magnesio, que forman compuestos insolubies con la cal liberada en el hormigón durante su endurecimiento.

b) Sillicatos alcalinos en disolución acuosa caliente.

c) Siliconas, con efecto semejante a los fluatos, aunque menos persistente.

d) Tetraftuoruro de slliclo, que tambièn reacciona con la cal liberada e, inciuso, con los aluminatos y silicatos del conglomerante. Procedimiento patentado.

5.- Revestimientos.-Muy acertadamente fijan los autores las condiciones-que no vacilan en calificar como duras-wexiglbles a los revestimientos protectores. Estas son:

1. Que el revestimiento ofrezca una superflcie uniforme exenta de poros o flsuras capaces de facilitar o permitir la entrada del agente corrosivo.

2. Flexibilidad suflciente para que las deformaciones, en régimen de trabajo, no produzcan grietas.

3. Inaiterabilldad frente a los ácidos, las bases y las bacterias.

4. Impermeabilidad al agua y a los gases.

5. Resistencia a la abrasión producida por los jiquidos o los sólidos en suspensión.

6. Fuerte adherencla a la superticie del hormigón.

7. Buen precio y facilidad de aplicación. 
Estas condtciones las cumplen, más o menos, los materiales siguientes:

I. Piezas cerámicas vitrlficadas.-Su empleo está condicionacio por la durabilidad de los materiales utilizados para la fijación de las placas y la colmatación de las juntas. Los autores citan las siguientes masillas:

a) Cemento de silicato sódico: Existen dos tipos que difleren en el proceso de fraguado, según se realice por deshidratación de la disoluclón de stlicato o por reacción entre el silicato $y$ un agente endurecedor adicionado al producto.

Estos revestimientos son más apropiados para ambientes y medios ácidos que para los neutroa 0 básicos, y no alcanzan una compacidad suficiente (Porosidad $=9 \%$ ).

b) Cementos de azufre, compuestos, principalmente, por azufre, cuarzo o carbón pulverizado y un agente plastificante. De uso muy extendido, son inertes frente a los ácidos diluídos y a muchos de ellos concentrados, asi como a los álcalis en concentraclones medias. No pueden emplearse con el ácido crómico, el nítrico de más de $40 \%$, y las soluciones alcalinas muy concentradas. Solubles en muchos disolventes orgánicos, y no resisten las temperaturas superiores a $95^{\circ} \mathrm{C}$.

c) Cementos de resinas fenol-formaldehido. Generalmente, se presentan como un liquido (que contiene de 70 a $80 \%$ de sólidos) portador de la resina y un sólido constituido por la carga (sílice o carbón) y el agente endurecedor; los productos se mezclan en el momento de su empleo. Estos mástiques de fenol resisten a los ácidos (excepto los oxidantes enérgicos), disolventes, álcalis diluídos, aceites y grasas, y vapor de agua hasta $180^{\circ} \mathrm{C}$. Su porosidad es inferior al $0,75 \%$.

d) Cementos de resinas furánicas.-Adoptados sólo hace unos diez años, se presentan como los anteriores bajo la forma de un líquido y un sólido para ser mezclados "in situ"; el fraguado suele durar, a la temperatura ordinaria, una hora. Prácticamente poseen las propiedades de las resinas fenólicas; se pueden utilizar frente a liquidos alcalinos de cualquier concentración y soportan bien el ataque de muchos ácidos y disolventes. Incluso se pueden emplear sin placas vitrificadas, armándoles con un tejido de lana de vidrlo.

II. Revestimlentos bituminosos.-Aplicables en caliente y en frío, se preparan a base de alqu1trán de hulla o de asfalto. Los primeros suelen apicarse en disolución; son muy impermeables, no se alteran por los ácidos minerales, pero se reblandecen en contacto prolongado con aceites minerales o vegetales. Los obtenidos a base de as-

falto poseen menor resistencia; algunos llegan a presentar una absorción para el agua del $37 \%$ y, en general, la protección frente a Ios ácidos fuertes es poco efectiva y duradera.

III. Revestimientos con materiales plásticos. La divulgación de sus caracteres constituye el princlpal objeto de la ponencia. Tras unos párrafos dedicados a definiciones y clasifleación de estos materiales, se describen las formas de utiiización de los mismos, princtpalmente en la protección de tuberías. Se citan:

Placas prefabricadas.-Ia colocación del plástíco en láminas, sea interior o exteriormente, según la situación del ambiente agresivo, se realiza sobre el tubo ya fabricado o sobre el molde para el mismo. En este íltimo caso, las placas que deben proteger el interior del tubo poseen unos salientes en el sentido de las generatrices y de sección en $\mathrm{T}$ que faworecen extraordinariamente la sujeción de la placa a la masa de hormigón.

Ei Departamento de Obras Públicas de lá ciu-

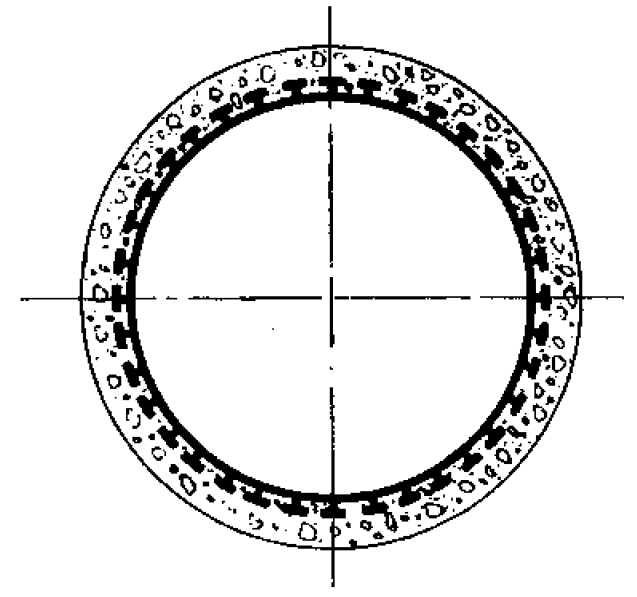

Fig. 1 dad de los Angeles, dió comienzo, en 1930, a los

estudios sobre las posibilidades que esta forma de protección sería capaz de rendir. Como ensayo se recubrió de plástico un tubo colocado en un medio muy agresivo; los exámenes posterlores no acusaron alteraciones, y ello dió lugar a que sólo en un año se recubrieron más de $10.000 \mathrm{~m}^{2}$ de tubería. Igual medida se adoptó para el nuevo colector, que complementará el suministro de agua a la ciudad hasta el año 2000; la superfleie revestida sobre pasa los $80.000 \mathrm{~m}^{2}$. Para las placas se utilizó un cloruro de polivinilo con inertes y plastificantes, resistentes al agua, oxidaciones, aceites, grasas, ácidos, sales y bacterias, e fmpermeable al $\mathrm{SH}_{\text {:. }}$.

Las placas, de 1,2 por $2,4 \mathrm{~m}$, se moldean a $165^{\circ} \mathrm{C}$ empleando una presión de $55 \mathrm{~kg} / \mathrm{cm}^{2}$, y su elasticidad es suflciente para absorber las deformaciones del hormigón; tienen un espesor de 1,5 mm $y$ presentan nervaduras paralelas en forma de $T$ de $6,5 \mathrm{~cm}$ (figura 1 ). 


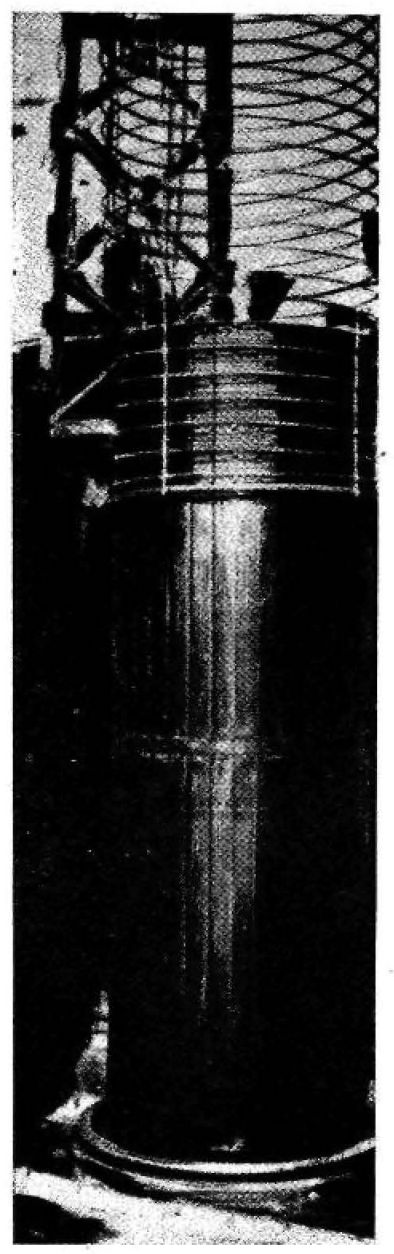

Fig. 2
Se utilizaron colocándolas sobre el molde interior del tubo, con la cara nervada orientada hacia la masa del hormigón. La soldadura entre las placas se logra con cintas de plástico superpuestas y soldadas mediante un soplete de aire caliente; un alambre de hierro mantiene las placas en posición correcta como puede apreciarse en las figuras 2 y 3 . En los tubos destinados a desagües, que no se llenan totalmente, el revestimiento sólo cubre la superficie comprendida bajo un ángulo de $270^{\circ}$, la cual se coloca, al utilizar el tubo, en una posición tal que corresponda a la parte sumergida del tubo. El coste de tales protecciones es, en Estados Unidos, del orden de 5 dólares por metro cuadrado y se puede aplicar a tubos de diámetros comprendidos entre 0,75 y 3 metros.

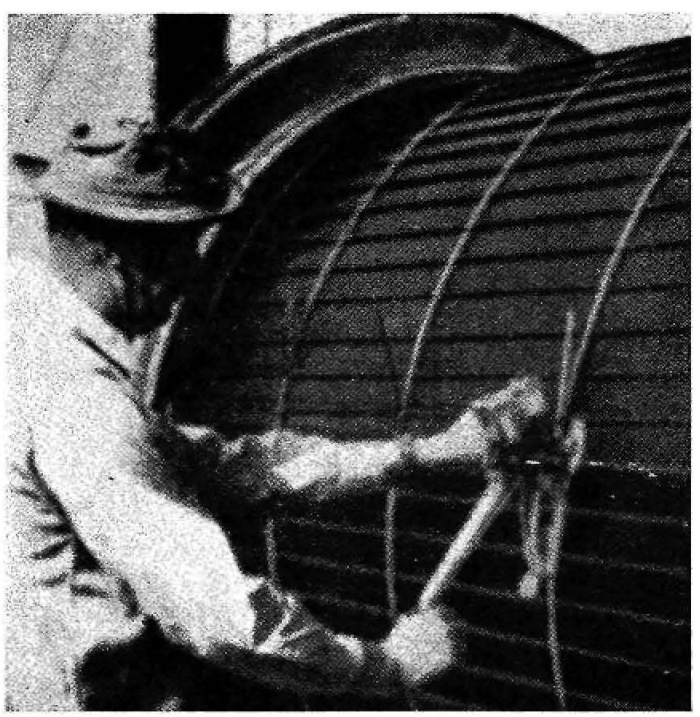

Fig. 3

Placas moldeadas sobre el tubo.-Esta forma de protección es utilizable no sólo para tuberías, sino en todo género de estructuras sometidas a reacciones agresivas. Consiste en aplicar "in situ" resinas poliéster reforzadas con fibra de vidrio. Se utiliza en depósitos, tuberías y estructuras, y puede colocarse igualmente en frío o en caliente.

Con fibra de vidrio como armadura, la resistencia a la tracción es del orden de $3.500 \mathrm{~kg} / \mathrm{cm}^{2}$; a la flexión, de $5.000 \mathrm{~kg} / \mathrm{cm}^{2}$, y a la compresión, de $2.500 \mathrm{~kg} / \mathrm{cm}^{2}$. El módulo de elasticidad varía entre 100.000 y $190.000 \mathrm{~kg} / \mathrm{cm}^{2}$; tiene un peso específico de 1,7 y resiste muy bien al ataque de ácidos, bases, sales y derivados del petróleo.

Se coloca mediante artificios que permiten proyectar, simultáneamente, la flbra de vidrio (cortada y orientada mecánicamente) y la resina; esto permite modificar el espesor del recubrimiento que posee una adherencia al hormigón de $40 \mathrm{~kg} / \mathrm{cm}^{2}$.

El procedimiento, cuya novedad le priva de referencias y experiencia suficientes para garantizar el buen resultado, ha tenido aplicación en las partes sumergidas y semisumergidas del trozo canadiense del canal del San Lorenzo; se aplicó, precedido de una limpieza con chorro de arena, en capas de 0,3 a $0,5 \mathrm{~mm}$ de espesor de una resina de butilato de vinilo, repitiendo la aplicación hasta alcanzar un espesor de 3 a 7 milímetros. 
Láminas.-Cuando no es necesario un espesor como los indicados anteriormente se utilizan láminas de plástico, de un espesor de algunas décimas de milímetro, que en el comercio se expenden en rollos. Es necesario disponer de un adhesivo adecuado.

Pinturas.-El procedimiento de aplicar pinturas de plástico con brocha, rulo o pistolete es el más fácil, aunque también es el de menor garantía.

Pinturas aicídicas.-El excelente resultado de estas pinturas en la protección de estructuras metálicas no se consigue cuando se las aplica a las superficies de hormigón. La gama de productos pertenecientes a este grupo, preparados por condensación de polialcoholes y poliácidos, es ilimitada. Poseen gran resistencia frente a los agentes atmosférỉcos y, cuando han secado, también resisten al alcohol, la gasolina y los lubricantes. Frente al agua y los ácidos resisten en medios gaseosos, pero no en medios líquidos. Les atacan los álcalis y, en general, son poco recomendables para el hormigón.

Pinturas fenólicas.-Muy resistentes a la humedad y a los productos químicos, son poco recomendables para el hormigón a causa de su vulnerabilidad frente a los álcalis.

Pinturas éster-epoxi.-Obtenidas por reacción entre las resinas epoxi y los aceites de lino o ricino deshidratados. Tampoco son aplicables a superficies de hormigón, pues no resisten el ataque de los á!calis.

Pinturas de cloro-caucho.-Para obtener con ellas una buena película es necesario que la proporción de sus componentes (caucho, cloro y plastificantes) sea lo más conveniente para el destino que se las quiera dar; cuando se acierta en esto, presenta el producto una excelente resistencia frente al agua, los ácidos y los álcalis. Han sido muy aplicadas en pavimentos, piscinas y depósitos, pero la duración de su efecto protector en los tubos parece aún dudosa.

Pinturas de vinilo._Las que contienen $87 \%$ de cloruro de vinilo parece que proporcionan los mejores recubrimientos. Resistentes al agua $\mathrm{y}$ al desgaste, son inatacables por los ácidos minerales, los álcalis y la mayoría de los productos químicos; poseen buena resistencia a los aceites y grasas, tanto minerales como vegetales, y son insolubles en los alcoholes y disolventes extraídos del petróleo.

La resistencia a los ácidos orgánicos, el amoníaco, los fenoles y los disolventes orgánicos es débil. Este tipo de pinturas ha sido utilizado con éxito en las estructuras de hormigón sometidas durante algunos decenios a la corrosión causada por gases y líquidos.

Resinas epoxi,-Obtenidas, recientemente, por condensación entre derivados del difenol y la epiclorhidrina, proporcionan, con ciertas aminas, un producto aplicable a pinturas, que posee una excelente adhesividad para el hormigón, resistencia a la abrasión, a los choques y a los productos químicos. Los productos que contienen estas resinas son muy durables en atmósferas húmedas y corrosivas, y la resistencia frente a los oxidantes (cloro) es mala. Se les utiliza en tuberías de desagüe, pero falta todavía experiencia sobre los resultados.

Los autores condensan su extensa, acertada y valiosa exposición en las siguientes

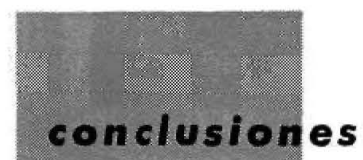

1. El hormigón, cuando ha sido bien preparado y su curado se ha realizado según las técnicas modernas, resiste muy bien las acciones agresivas de los materiales que le rodean. El empleo de revestimientos protectores sólo es aconsejable en los casos de fuerte agresividad.

2." En los casos excepcionales en que los agentes agresivos, ácidos, álcalis o sales, tienen una concentración muy alta, los revestimientos protectores pueden evitar la corrosión al incrementar la resistencia química. 
3." Una larga experiencla permite actualmente afirmar que la protección mediante placas de plásticos prefabricadas es satisfactoria.

4." Los métodos de proyección de plástico y armadura sobre la superficie del hormigón son muy prometedores y se debe dedicar mucha atenclón a los resultados.

5." Tamblén son interesantes los resultados que se obtengan con las pinturas plásticas.

6. El hormigón empleado en la fabricación de los tubos debe ser de la más alta calidad, incluso en los casos en que se utilice revestido con un material protector; éste tiene por única misión - como su nombre indica-proteger al hormigón sin reemplazarlo en sus cometidos de impermeabilidad y resistencia.

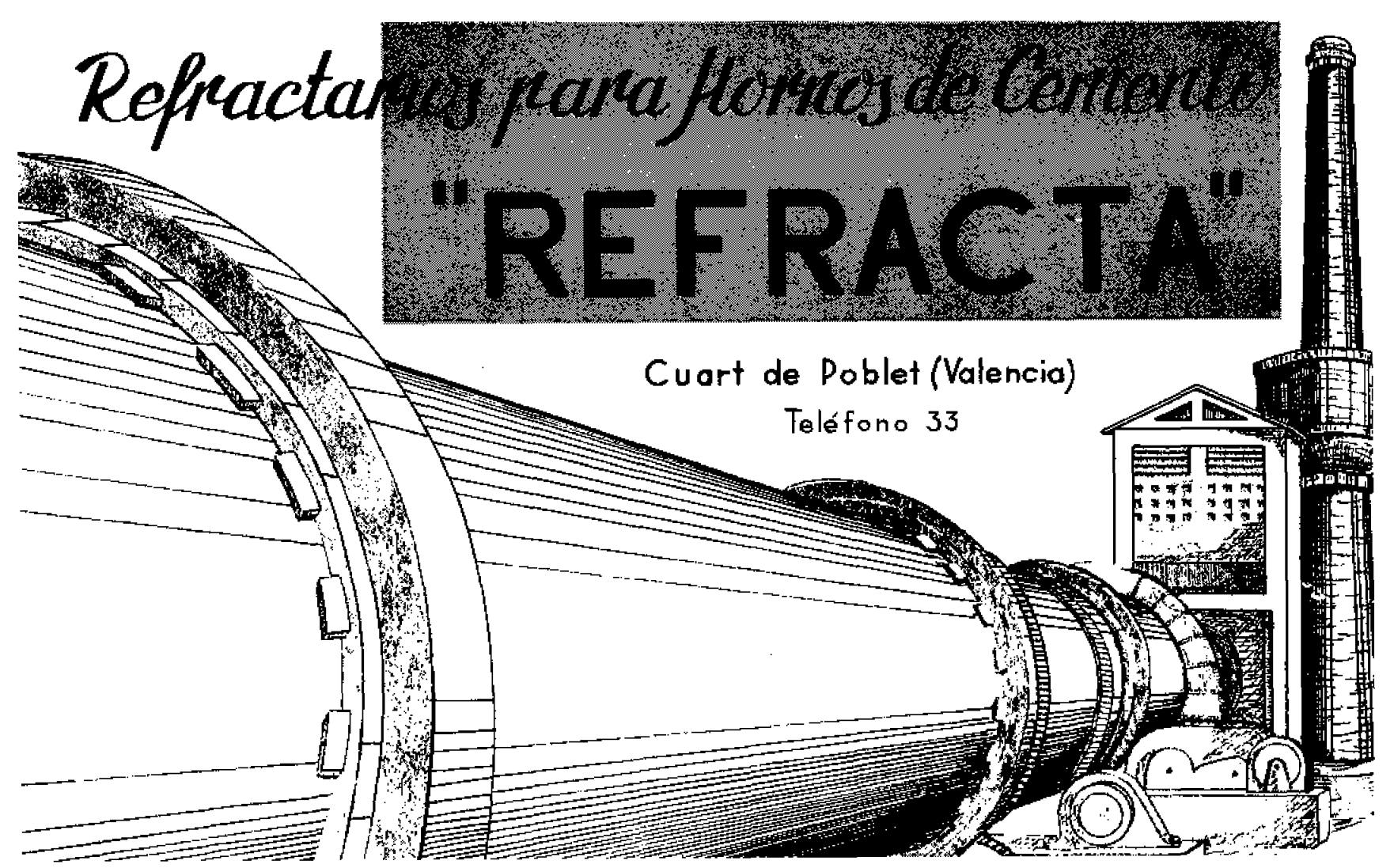

